\title{
Análise da Carga Física de Trabalho e Biomecânica na Construção de Telhados Com Estruturas de Madeira
}

\author{
Rômulo Maziero ${ }^{1}$, Nilton Cesar Fiedler ${ }^{2}$, \\ Pedro Gutemberg de Alcântara Segundinho², \\ Flávio Cipriano de Assis do Carmo ${ }^{2}$
}

\author{
${ }^{1}$ Programa de Pós-Graduação em Engenharia Metalúrgica e de Materiais - PROPEMM, \\ Instituto Federal de Educação, Ciência e Tecnologia do Espírito Santo - IFES, Vitória/ES, Brasil \\ ${ }^{2}$ Departamento de Ciências Florestais e da Madeira - DCFM, Centro de Ciências Agrárias e Engenharias - CCA, \\ Universidade Federal do Espírito Santo - UFES, Jerônimo Monteiro/ES, Brasil
}

\begin{abstract}
RESUMO
Com o crescimento das estruturas de madeira na construção civil, em especial na construção de telhados, surgiu nas empresas a preocupação com a qualidade de vida e segurança dos trabalhadores. A pesquisa teve como objetivo a análise da carga física de trabalho (monitor de frequência cardíaca) e postura (metodologia de MICHIGAN). O trabalho foi realizado nos municípios de Alegre, Jerônimo Monteiro e São José do Calçado, localizados no sul do Estado do Espírito Santo. Realizou-se a coleta de dados em três canteiros de obra, durante os meses de setembro de 2010 a maio de 2012, analisando-se 18 trabalhadores. Na análise da carga física de trabalho, as atividades de montagem das treliças, das terças, dos caibros e das ripas foram classificadas como pesadas, sendo necessárias pausas para descanso. As posturas dos trabalhadores levantadas na montagem das ripas são prejudiciais à saúde, demandando a adoção de medidas ergonômicas urgentes.
\end{abstract}

Palavras-chave: ergonomia, construção civil, ambiente de trabalho.

\section{Analysis of Physical Workload and Biomechanics in the Construction of Roofs in Wooden Frames}

\begin{abstract}
With the growing use of wooden frames in construction, particularly in the roofs, companies are concerned with workers quality of life and safety. The research aimed to analyze the physical workload (heart rate monitor) and posture (MICHIGAN methodology). The study was conducted in the municipalities of Alegre, Jerome Monteiro and São José do Calçado, located in southern Espírito Santo. Data was collected in three construction sites during the months of September 2010 to May 2012, analyzing 18 workers. In the analysis of physical workload, activities for the installation of trusses, purlins, rafters and battens, were classified as heavy, requiring rest times. Workers' posture during the slats assembly favors injuries and requires the adoption of urgent ergonomic measures.
\end{abstract}

Keywords: ergonomics, construction, work environment. 


\section{INTRODUÇÃO}

A ergonomia é o conjunto de conhecimentos a respeito do desempenho do ser humano nas atividades, a fim de aplicá-lo à realização das tarefas, aos instrumentos, às máquinas e aos sistemas de produção (Iida, 2005).

A preocupação com o bem-estar, a saúde e segurança do ser humano no trabalho, seja ele pesado ou leve, vem se acentuando no decorrer dos últimos anos (Silva, 1999). A ergonomia procura adequar o trabalho ao ser humano (Iida, 2005), propiciando a melhor satisfação e o bem-estar do trabalhador, para que possa produzir com qualidade e produtividade.

O ser humano possui grande capacidade para ajustar-se às condições de exposição que lhe são impostas, adaptando-se rapidamente às situações (Couto, 1995). Assim, tem capacidade para manusear máquinas, ferramentas e equipamentos mal projetados ergonomicamente, suportando posições incômodas e inadequadas ao trabalho. No entanto, para Minette (1996), ao se realizar um trabalho em condições inóspitas perdas ocorrem na produtividade e a saúde pode ser severamente prejudicada. Esses fatores, segundo Fiedler et al. (2006), causam desconforto, aumentam o risco de acidentes e podem provocar danos consideráveis à saúde, sendo que grande parte das lesões decorrentes do risco ergonômico é do tipo trauma cumulativo, ou seja, o trabalhador somente irá perceber os efeitos deletérios depois de alguns anos numa situação de trabalho que, a princípio, considerava até aceitável.

Nas avaliações de trabalhos que exigem elevado esforço físico deve ser observado o tipo de tarefa com relação ao desgaste físico requerido, considerando o metabolismo, o consumo energético, as pausas, a alimentação, a postura escolhida e o ambiente físico de trabalho (Fiedler et al., 2008). Quando a atividade exigir manuseio de materiais, os principais fatores que interferem são o desgaste energético e as posturas, quando impostas e não variando ao longo do tempo (Waters et al., 1993).

Tais fatores, na construção civil, oferecem inúmeros riscos aos trabalhadores, riscos esses que na maioria das vezes acometem a saúde do trabalhador (Mansilla, 2010). Outro grave problema, segundo Ribeiro et al. (2005), é que os trabalhadores menosprezam os riscos existentes no ambiente de trabalho, exigindo assim por parte dos responsáveis um trabalho constante de conscientização dos riscos.

As atividades desempenhadas dentro da construção civil, como a construção de telhados com estruturas de madeira, podem expor os trabalhadores a movimentos repetitivos e ambientes insalubres. O trabalho normalmente é ao ar livre e os serviços executados são predominantemente manuais, expondo ainda mais o trabalhador a exercer um grande esforço físico. Segundo Alvarez (1996), as características de um ambiente de trabalho refletem, de maneira expressiva, as qualidades do trabalhador.

A melhoria das condições de trabalho é, prioritariamente, um processo de transformação social, cabendo ao conhecimento científico determinar os fundamentos dessa transformação. O estudo do trabalho e a aplicação prática dos resultados permitem a consolidação desse projeto de transformação.

O presente trabalho teve como objetivo avaliar a carga física de trabalho e a biomecânica na construção de telhados com estruturas de madeira, fornecendo subsídios para uma organização ou reorganização ergonômica do trabalho, visando melhoria da saúde, qualidade de vida, segurança e produtividade dos trabalhadores.

\section{MATERIAL E MÉTODOS}

\subsection{Local de estudo}

O trabalho foi realizado em três canteiros de obra, variando de 282,23 $\mathrm{m}^{2}$ a 347,41 $\mathrm{m}^{2}$ de edificações, na região sul do Estado do Espírito Santo, nos municípios de Alegre, Jerônimo Monteiro e São José do Calçado, de acordo com a Figura 1.

\subsection{Amostragem da população}

A pesquisa foi realizada a partir de um estudo piloto de todas as tarefas analisadas, buscando-se definir o número mínimo de dados necessários para proporcionar um erro de amostragem máximo de $5 \%$, segundo a metodologia proposta por Conaw (1977), por meio da Equação 1:

$n \geq \frac{t^{2} \cdot s^{2}}{e^{2}}$ 


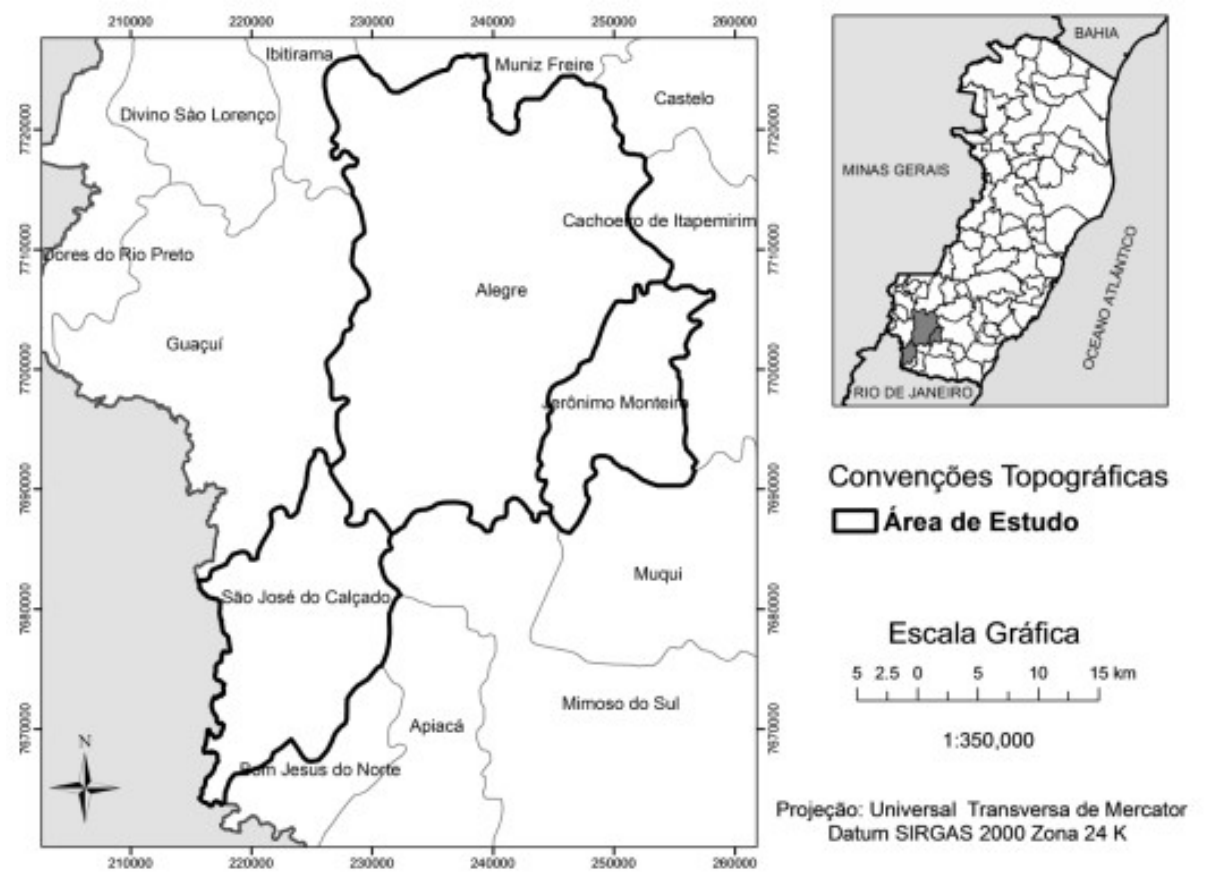

Figura 1. Localização da região de estudo, em Alegre, Jerônimo Monteiro e São José do Calçado, ES.

Figure 1. Location of the study area in Alegre, Jerome Monteiro and St. Joseph's Footwear, ES.

em que n é o número de trabalhadores, t o coeficiente tabelado a $5 \%$ de probabilidade (distribuição de Student), s o desvio padrão da amostra e e o erro admissível a $5 \%$ da média aritmética dos dados.

Os dados relativos a análise ergonômica do trabalho foram coletados em uma população de 18 trabalhadores.

\subsection{Coleta de dados}

A coleta de dados foi realizada respeitando-se o número mínimo de amostras estabelecidas no estudo piloto, garantindo a precisão da pesquisa. Após a coleta de dados realizada nos meses de setembro de 2010 a maio de 2012, foi desenvolvida uma planilha para cada atividade estudada, contendo a carga física de trabalho e a análise biomecânica dos trabalhadores. Em seguida foi realizado o levantamento da madeira utilizada nas obras visitadas e das seções comerciais, que serviu de base para a análise de posturas decorrentes do levantamento e dos movimentos dos trabalhadores.

\subsection{Descrição das atividades}

Foram acompanhadas as seguintes atividades do processo de construção de telhados, montagem das treliças: união com pinos metálicos (pregos e parafusos) e/ou cavilhas de madeira, as peças do banzo superior, banzo inferior, montante e diagonal; montagem das terças: fixação com pregos e/ou parafusos sobre as treliças, pontaletes ou paredes, servindo de sustentação dos caibros; montagem dos contraventamentos: ligação de uma treliça a outra por meio de peças de madeira; montagem dos caibros: união com pregos sobre as terças, servindo de sustentação para as ripas; e montagem das ripas: fixação com pregos sobre os caibros, para sustentação das telhas. O trabalho deteve-se na Análise Ergonômica do Trabalho (AET) da armação em madeira de telhados de duas águas ("V" invertido), não sendo realizadas coletas de dados durante o cobrimento das estruturas com telhas.

\subsection{Análises realizadas}

\subsubsection{Análise da carga física de trabalho}

A carga física de trabalho foi avaliada com o uso de um monitor de frequência cardíaca da marca POLAR, modelo RS300X, instalado no trabalhador.

O equipamento é formado por um receptor digital de pulso, uma correia elástica e um transmissor com eletrodos que foram fixados na altura do tórax do trabalhador, por meio da correia elástica. Os batimentos 
cardíacos foram armazenados no receptor de pulso em intervalos de 15 segundos. Após a coleta de dados, os valores foram transferidos para o computador com a utilização da interface que acompanha o equipamento e, por intermédio de software específico, foram realizadas análises.

Com esses dados foi possível determinar a carga física de trabalho imposta em cada atividade e estabelecer os limites aceitáveis para um desempenho contínuo no trabalho, bem como ajustar a carga física de trabalho à capacidade dos trabalhadores. Essa classificação laboral foi baseada na metodologia proposta por Apud (1997), dependente da frequência cardíaca média por atividade durante a construção de estruturas de telhado em madeira.

Com essas análises foi possível calcular a carga cardiovascular no trabalho (Apud, 1997), que corresponde à frequência cardíaca máxima utilizável. O valor dessa carga foi calculado pela Equação 2:

$C C V=\frac{F C T-F C R}{F C M-F C R} \times 100$

em que CCV é a carga cardiovascular (\%), FCT, a frequência cardíaca de trabalho (bpm), FCR, a frequência cardíaca de repouso (bpm), FCM, a frequência cardíaca máxima (220 - idade em anos).

Para realização de um trabalho contínuo sem riscos para a saúde, a carga cardiovascular, segundo Apud (1997), não deve ser superior a $40 \%$ em um turno de trabalho de 8 horas. Nos casos em que a carga cardiovascular foi superior a esse valor calculou-se a frequência cardíaca limite (FCL) utilizando-se a Equação 3:

$F C L=0,40 \times(F C M-F C R)+F C R$

Nas análises em que a carga cardiovascular ultrapassou esse valor de $40 \%$, para reorganização do trabalho foi determinado o tempo de repouso (pausa) necessário, por hora de trabalho, pela Equação 4:

$T r=\frac{H t(F C T-F C L)}{F C T-F C R}$

em que Tr é o tempo de repouso, descanso ou pausa (minutos) e Ht, o tempo de trabalho (minutos).

\subsubsection{Análise biomecânica (3D SSPPTM)}

A avaliação biomecânica foi realizada por meio da análise tridimensional, utilizando a técnica de filmagem e gravação. As posturas usuais foram "congeladas", para medição dos ângulos dos diversos segmentos corpóreos. As forças envolvidas foram medidas utilizando-se um dinamômetro digital portátil da marca FORCE GAUGE, modelo FG-5100.

Foram medidos os ângulos dos seguintes segmentos corpóreos: cotovelo, ombro, dorso, coxofemural, joelho, tornozelo e disco vertebral $\mathrm{L}_{5}-\mathrm{S}_{1}$. Além disso foram fornecidos o valor, a magnitude e a direção das forças aplicadas; o número de mãos utilizadas; e os dados antropométricos de altura e peso da população envolvida, conforme metodologia de MICHIGAN (University of Michigan, 2011).

Esses dados foram analisados por meio do programa computacional do modelo biomecânico tridimensional de predição de posturas e forças estáticas (3D Static Strength Prediction Program ${ }^{\mathrm{TM}}$ - 3D SSPP ${ }^{\mathrm{TM}}$ ) desenvolvido pelo Centro de Ergonomia da Universidade de Michigan (MICHIGAN), dos Estados Unidos.

A análise por meio do programa $3 \mathrm{D} \mathrm{SSPP}^{\mathrm{TM}}$ forneceu a carga-limite recomendada. Essa carga-limite recomendada pela metodologia de MICHIGAN induz a uma força (medida em Newton) de compressão da ordem de $3.426,3 \mathrm{~N}$ sobre o disco vertebral $\mathrm{L}_{5}-\mathrm{S}_{1}$, que pode ser tolerada pela maioria dos trabalhadores jovens e em boas condições de saúde (Silva, 2003).

\section{RESULTADOS E DISCUSSÃO}

\subsection{Número de trabalhadores avaliados em cada atividade}

O número de trabalhadores foi atendido em todas as atividades e correspondeu à necessidade da uniformidade das coletas para a realização do teste estatístico, conforme descrito na Tabela 1 .

Tabela 1. Número de trabalhadores necessários para um erro admissível de 5\%.

Table 1. Number of workers required for an admissible error of $5 \%$

\begin{tabular}{|cc|}
\hline Atividade & $\mathbf{N}^{\circ}$ de trabalhadores \\
\hline Montagem das treliças & 3 \\
\hline Montagem das terças & 3 \\
\hline $\begin{array}{c}\text { Montagem dos } \\
\text { contraventamentos }\end{array}$ & 2 \\
\hline Montagem dos caibros & 5 \\
\hline Montagem das ripas & 5 \\
Total & 18 \\
\hline
\end{tabular}




\subsection{Carga física de trabalho}

Na Tabela 2 são descritos os resultados por atividade analisada referentes a idade média dos trabalhadores, frequência cardíaca média no trabalho, frequência cardíaca média em repouso, frequência cardíaca média máxima, carga cardiovascular, frequência cardíaca limite, tempo de repouso necessário e classificação do trabalho.

As atividades de maior carga física de trabalho na construção de telhados com estrutura de madeira foram as atividades de montagem das treliças, das terças, dos caibros e das ripas, classificadas como pesadas, com frequência cardíaca média no trabalho de 130 bpm, 128 bpm, 137 bpm e 135 bpm, e carga cardiovascular de $52 \%$, 48\%, 55\% e 58\%, respectivamente, sendo assim, estão acima do limite máximo de 40\%. Para que não ultrapasse o limite de $40 \%$, a frequência cardíaca no trabalho não deve ultrapassar o limite de 120 bpm, segundo Apud (1997). Portanto, deve ser reorganizado o ambiente de trabalho, prevendo-se um tempo de repouso médio de 13 minutos por hora trabalhada para a atividade de montagem das treliças, 10 minutos por hora trabalhada para a atividade de montagem das terças, 16 minutos por hora trabalhada para a atividade de montagem dos caibros e 19 minutos por hora trabalhada para a atividade de montagem das ripas, para que não ocorra perda de rendimento pela sobrecarga física, visando com isso o bem-estar do trabalhador.

A atividade de menor frequência cardíaca média no trabalho foi a montagem dos contraventamentos, classificada como moderadamente pesada, com frequência cardíaca média no trabalho de 124 bpm, o que demanda um tempo de repouso médio de 5 minutos por hora trabalhada.

\subsection{Análise de posturas}

A análise das posturas mais frequentes adotadas pelos trabalhadores foi realizada com o intuito de conhecer e quantificar os riscos biomecânicos que envolvem a construção de estruturas de telhados em madeira. De acordo com a NR-17 (Ergonomia), não deve ser exigido nem admitido o transporte manual, por um trabalhador, de cargas cujo peso seja suscetível de comprometer a sua saúde ou segurança.

Para a análise de posturas foi utilizada a Manilkara spp. como referência, espécie essa empregada na construção das estruturas dos telhados estudados. A madeira era procedente de Bom Jesus do Norte e Iúna, ES, e as seções das peças componentes da armação dos telhados comumente comercializadas no Estado do Espírito Santo são: terças: seção de $6,0 \mathrm{~cm} \times 12,0 \mathrm{~cm} ; 6,0 \mathrm{~cm} \times 16,0 \mathrm{~cm}$; $8,0 \mathrm{~cm} \times 16,0 \mathrm{~cm} ; 10,0 \mathrm{~cm} \times 20,0 \mathrm{~cm}$; caibros: seção de $5,0 \times 6,0 \mathrm{~cm} ; 5,0 \mathrm{~cm} \times 8,0 \mathrm{~cm} ; 6,0 \mathrm{~cm} \times 6,0 \mathrm{~cm}$; $6,5 \mathrm{~cm} \times 4,0 \mathrm{~cm}$; ripas: seção de $1,0 \mathrm{~cm} \times 5,0 \mathrm{~cm}$; $1,5 \mathrm{~cm} \times 5,0 \mathrm{~cm} ; 2,5 \mathrm{~cm} \times 2,5 \mathrm{~cm} ; 2,5 \mathrm{~cm} \times 5,0 \mathrm{~cm}$; treliças (montante, diagonal, banzo superior, banzo inferior): $8,0 \mathrm{~cm} \times 8,0 \mathrm{~cm} ; 8,0 \mathrm{~cm} \times 12,0 \mathrm{~cm} ; 8,0 \mathrm{~cm} \times 16,0 \mathrm{~cm}$; $10,0 \mathrm{~cm} \times 20,0 \mathrm{~cm}$; contraventamentos: seção de $6,0 \mathrm{~cm} \times 5,0 \mathrm{~cm} ; 6,0 \mathrm{~cm} \times 8,0 \mathrm{~cm} ; 6,0 \mathrm{~cm} \times 12,0 \mathrm{~cm} ;$ $6,0 \mathrm{~cm} \times 16,0 \mathrm{~cm}$.

Nas Tabelas 3, 4, 5, 6 e 7 são mostradas as análises das principais posturas adotadas pelos trabalhadores durante a movimentação das peças de Manilkara spp., inicialmente, as de menor peso e comprimento e, posteriormente, as de maior peso e comprimento.

Tabela 2. Avaliação da carga física de trabalho exigida nas atividades estudadas.

Table 2. Evaluation of physical workload required in the activities studied.

\begin{tabular}{|c|c|c|c|c|c|c|c|c|}
\hline \multirow[t]{2}{*}{ Atividade } & $\begin{array}{l}\text { Idade } \\
\text { média }\end{array}$ & FCR & FCT & FCL & FCM & CCV & $\operatorname{Tr}$ & \multirow{2}{*}{$\begin{array}{l}\text { Classificação do } \\
\text { trabalho }\end{array}$} \\
\hline & (anos) & (bpm) & (bpm) & (bpm) & (bpm) & $(\%)$ & $(\mathrm{min} / \mathrm{h})$ & \\
\hline Montagem das treliças & 34 & 69 & 130 & 116 & 186 & 52 & 13 & Pesado \\
\hline Montagem das terças & 32 & 71 & 128 & 118 & 188 & 48 & 10 & Pesado \\
\hline $\begin{array}{c}\text { Montagem dos } \\
\text { contraventamentos }\end{array}$ & 28 & 70 & 124 & 119 & 192 & 44 & 5 & Mod. Pesado \\
\hline Montagem dos caibros & 33 & 76 & 137 & 120 & 187 & 55 & 16 & Pesado \\
\hline Montagem das ripas & 41 & 73 & 135 & 115 & 179 & 58 & 19 & Pesado \\
\hline
\end{tabular}

$\mathrm{FCT}_{\mathrm{bpm}}=$ Frequência Cardíaca de Trabalho; $\mathrm{CCV}_{\%}=$ Carga Cardiovascular; $\mathrm{FCL}_{\mathrm{bpm}}=$ Frequência Cardíaca Limite; $\mathrm{FCR}_{\mathrm{bpm}}=$ Frequência Cardíaca de Repouso; $\mathrm{FCM}_{\mathrm{bpm}}=$ Frequência Cardíaca Máxima; $\operatorname{Tr}_{\min / \mathrm{h}}=$ Tempo de Repouso. 
Tabela 3. Análise biomecânica da atividade de montagem das treliças pela metodologia de MICHIGAN. Table 3. Biomechanical analysis of the activity of assembling the trusses, the methodology MICHIGAN.

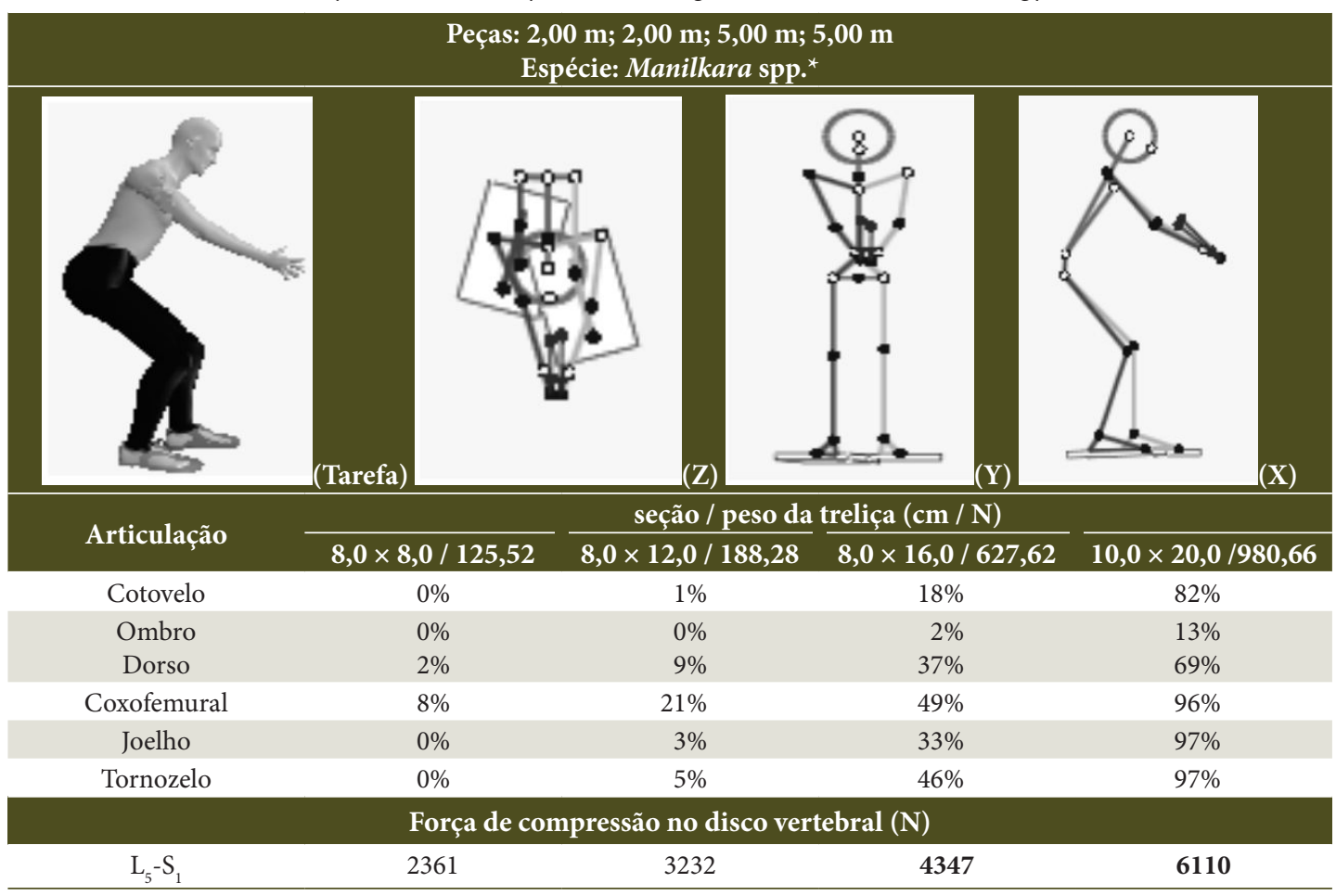

${ }^{*} \rho_{\text {ap, } 12}=1.143 \mathrm{~kg} / \mathrm{m}^{3} ; \rho_{\text {básica }}=970 \mathrm{~kg} / \mathrm{m}^{3}$.

Tabela 4. Análise biomecânica da atividade de montagem das terças pela metodologia de MICHIGAN. Table 4. Biomechanical analysis of the activity of assembling Tuesdays, the methodology MICHIGAN.

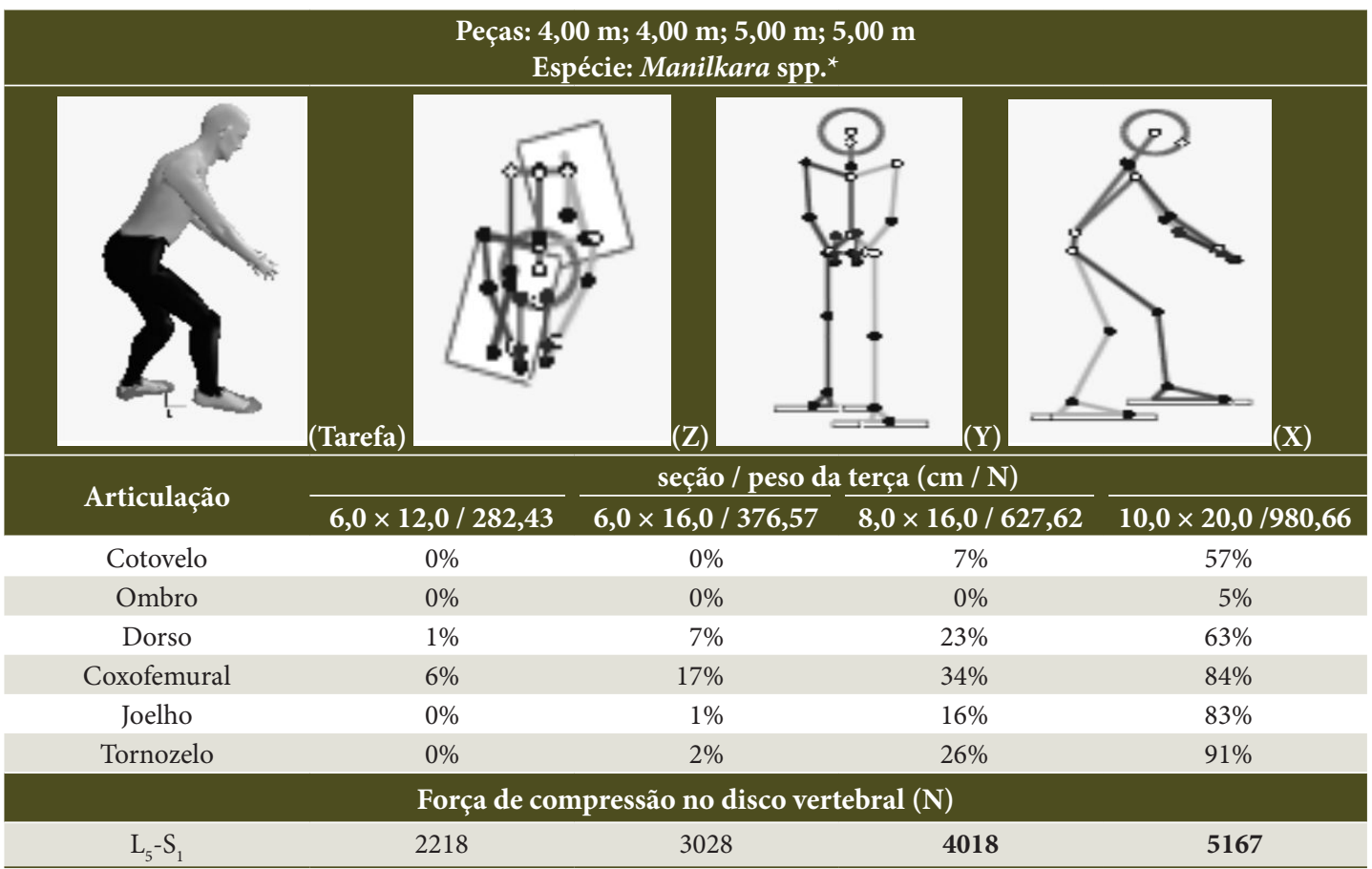

${ }^{*} \rho_{\text {ap, }, 12}=1.143 \mathrm{~kg} / \mathrm{m}^{3} ; \rho_{\text {básica }}=970 \mathrm{~kg} / \mathrm{m}^{3}$. 
Tabela 5. Análise biomecânica da atividade de montagem dos contraventamentos pela metodologia de MICHIGAN. Table 5. Biomechanical analysis of the activity of fitting of braces, the methodology MICHIGAN.

Peças: 4,27 m; 4,27 m; 4,27 m; 4,27 m
Espécie: Manilkara spp.*

${ }^{*} \rho_{\text {ap, }, 12}=1.143 \mathrm{~kg} / \mathrm{m}^{3} ; \rho_{\text {básica }}=970 \mathrm{~kg} / \mathrm{m}^{3}$.

Tabela 6. Análise biomecânica da atividade de montagem dos caibros pela metodologia de MICHIGAN.

Table 6. Biomechanical analysis of the activity of assembling the rafters, the methodology MICHIGAN.

Peças: 4,00 m; 4,00 m; 4,00 m; 4,00 m
Espécie: Manilkara spp.*

${ }^{*} \rho_{\text {ap, }, 12}=1.143 \mathrm{~kg} / \mathrm{m}^{3} ; \rho_{\text {básica }}=970 \mathrm{~kg} / \mathrm{m}^{3}$. 
Tabela 7. Análise biomecânica da atividade de montagem das ripas pela metodologia de MICHIGAN.

Table 7. Biomechanical analysis of the activity of assembling the slats, the methodology MICHIGAN.

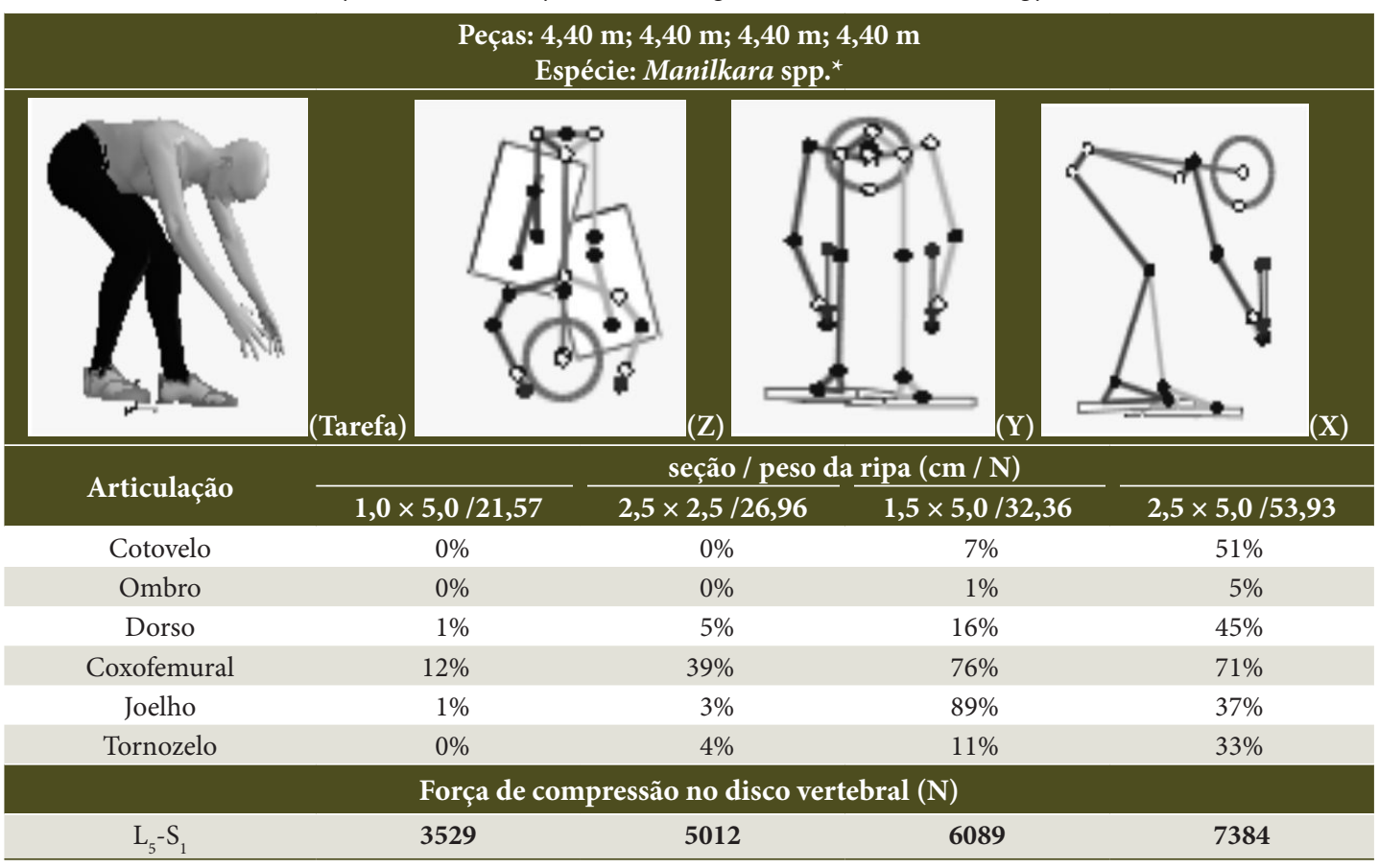

${ }^{*} \rho_{\text {ap, }, 12}=1.143 \mathrm{~kg} / \mathrm{m}^{3} ; \rho_{\text {básica }}=970 \mathrm{~kg} / \mathrm{m}^{3}$.

De acordo com a metodologia de MICHIGAN, há riscos significativos de lesão nas articulações, sendo que a partir de peças com seção de $8,0 \mathrm{~cm} \times 12,0 \mathrm{~cm}$ o risco de lesão passa de baixo para moderado nas articulações do dorso e coxofemural ( $9 \%$ e $21 \%$ ), evidenciando-se a necessidade de intervenções de melhoria ergonômica para que os trabalhadores movimentem peças com essa seção realizando o trabalho nessa postura. Os problemas de compressão no disco vertebral $\mathrm{L}_{5}-\mathrm{S}_{1}$ começam a ocorrer a partir do trabalho de movimentação de peças com seção de $8,0 \mathrm{~cm} \times 16,0 \mathrm{~cm}$, no qual o valor é superior a Carga Limite de Compressão no Disco (CLCD), que é de $3.426,3 \mathrm{~N}$. Isso indica que as peças com seção igual ou superior podem oferecer grandes riscos de lesão à coluna vertebral dos trabalhadores.

De acordo com a metodologia de MICHIGAN, há riscos significativos de lesão nas articulações, principalmente para a coxofemural, seguida pelas articulações de tornozelo, dorso e joelho. A partir de peças com seção de $6,0 \mathrm{~cm} \times 16,0 \mathrm{~cm}$, o risco de lesão passa de baixo para moderado na articulação coxofemural (17\%), evidenciando a necessidade de intervenções de melhoria ergonômica para que os trabalhadores movimentem peças com essa seção realizando o trabalho nessa postura. Nota-se ainda que a partir de peças com seção de 10,0 cm × 20,0 cm o risco de lesão para essa articulação passa a ser alto (84\%), o que tornaria inviável a execução dessa atividade com essa carga.

De acordo com a metodologia de MICHIGAN, há riscos significativos de lesão nas articulações, sendo que a partir de peças com seção de $6,0 \mathrm{~cm} \times 5,0 \mathrm{~cm}$ há risco moderado de lesão nas articulações coxofemural, de joelho e tornozelo (17\%, 13\% e 9\%). Nota-se ainda que a partir de peças com seção de $6,0 \mathrm{~cm} \times 8,0 \mathrm{~cm}$ o risco de lesão para as articulações passa a ser alto para as articulações coxofemural, de joelho e tornozelo (54\%, $67 \%$ e 51\%), o que tornaria inviável a execução dessa atividade a partir dessa carga.

A partir de peças com seção de $6,5 \mathrm{~cm} \times 4,0 \mathrm{~cm}$, há risco moderado e alto de lesão às articulações coxofemural, de joelho e tornozelo (respectivamente $(29 \%, 17 \%$ e $21 \%)$. Não há riscos significativos quanto à compressão no disco vertebral $\mathrm{L}_{5}-\mathrm{S}_{1}$ para essa postura com as cargas avaliadas. 
De acordo com a metodologia de MICHIGAN, há riscos significativos de lesão nas articulações em todos os pesos avaliados. A partir de peças com seção de $1 \mathrm{w}, 0 \mathrm{~cm} \times 5,0 \mathrm{~cm}$, o risco de lesão passa de moderado para alto na articulação coxofemural (12\%), evidenciando que, adotando-se essa postura, é inviável a execução dessa atividade com essa carga. Os problemas de compressão no disco vertebral $\mathrm{L}_{5}-\mathrm{S}_{1}$ começam a ocorrer a partir do trabalho de movimentação de peças com seção de $1,0 \mathrm{~cm} \times 5,0 \mathrm{~cm}$ onde o valor $(3.529 \mathrm{~N})$ é superior a CLCD. Isso indica que peças com seção igual ou superior a essa podem oferecer grandes riscos de lesão à coluna vertebral dos trabalhadores.

\section{CONCLUSÕES}

Constatou-se que a montagem dos contraventamentos apresentou-se como a de menor exigência física em relação às outras atividades, com isso, além de se planejar o processo construtivo das estruturas do telhado em madeira, devem ser aplicadas pausas de acordo com cada tarefa. A análise postural realizada por meio da metodologia de MICHIGAN provou que as posturas adotadas pelos trabalhadores durante a atividade de montagem das ripas devem ser corrigidas, evitando-se que esses tipos de posturas sejam rotinas frequentes entre os trabalhadores, o que pode ser solucionado com treinamento postural periódico. Como continuidade deste trabalho, o estudo da cobertura com telhas é uma das propostas para novas investigações, no âmbito de se analisarem as dificuldades ergonômicas nessa atividade pós-armação de telhados, conscientizando-se não só os trabalhadores sobre a importância da ergonomia e segurança no trabalho, mas também tornando prioridade, por parte dos contratantes, a aplicação das mesmas no ambiente de trabalho.

\section{AGRADECIMENTOS}

À Digien Engenharia e à Serraria São Francisco, pelo apoio na coleta de dados, em especial ao engenheiro Clóvis, ao engenheiro Henrique e ao oficial pleno Lúcio Flávio pela enorme ajuda no desenvolvimento desta pesquisa. À Vale e à Concremat Engenharia, pelo pronto atendimento e disponibilidade, em especial ao engenheiro Marcello, ao engenheiro Antônio e à Técnica em Segurança do Trabalho Dalva Maria Volponi Rodrigues, dispostos a colaborarem com o estudo.
À Rio Pardo Madeiras, em especial ao sócio-gerente Antônio João, pelo apoio. Aos trabalhadores que se dispuseram a ajudar na concretização deste trabalho.

\section{STATUS DA SUBMISSÃO}

Recebido: 29 dez., 2013

Aceito: 3 fev., 2017

\section{AUTOR(ES) PARA CORRESPONDÊNCIA}

\section{Rômulo Maziero}

Departamento de Ciências Florestais e da Madeira - DCFM, Centro de Ciências Agrárias e Engenharias - CCA, Universidade Federal do Espírito Santo - UFES, Av. Gov. Lindemberg, $n^{\circ}$ 316, Centro, CEP 29550-000, Jerônimo Monteiro, ES, Brasil

e-mail: maziero.ufes@gmail.com

\section{REFERENCIAS}

Alvarez BR. Qualidade de vida relacionada à saúde de trabalhadores: um estudo de caso [dissertação]. Florianópolis: Universidade Federal de Santa Catarina; 1996.

Apud E. Temas de ergonomia aplicados al aumento de la productividad de la mano de obra en cosecha florestal. In: Anais do $3^{\circ}$ Simpósio Brasileiro Sobre Colheita E Transporte Florestal; 1997; Vitória. Vitória: SIF: DEF; 1997. p. 46-60.

Conaw PL. Estatística. São Paulo: Edgard Blucher Ltda; 1977. 264 p.

Couto HA. Ergonomia aplicada ao trabalho: o manual técnico da máquina humana. Belo Horizonte: Ergo; 1995. 353 p.

Fiedler NC, Rodrigues TO, Medeiros MB. Avaliação das condições de trabalho, treinamento, saúde e segurança de brigadistas de combate a incêndios florestais em unidades de conservação do Distrito Federal. Revista Árvore 2006; 30(1): 55-63. http://dx.doi.org/10.1590/ S0100-67622006000100008.

Fiedler NC, Wanderley FB, Guimarães PP, Alves RT. Avaliação dos limites recomendados de pesos no manuseio de cargas em marcenarias. Revista Cerne 2008; 14(2): 133-140.

Iida I. Ergonomia: projeto e produção. 2. ed. São Paulo: Edgard Blucher Ltda; 2005. 630 p.

Mansilla G. Análise dos riscos ergonômicos da atividade de armação na construção civil em canteiro de obras de Três Lagoas, MS [especialização]. Mato Grosso: Universidade Federal de Mato Grosso; 2010. 
Minette LJ. Análise de fatores operacionais e ergonômicos na operação de corte florestal com motosserra [tese]. Viçosa: Universidade Federal de Viçosa; 1996.

Ribeiro SB, Souto MM, Araújo IC Jr. Análise dos riscos ergonômicos da atividade do gesseiro em um canteiro de obras na cidade de João Pessoa, $\mathrm{PB}$, através do software WinOWAS. Revista Gestão Industrial 2005; v. 1, n. 4, p. 528-535.

Silva, K. R. Análise de fatores ergonômicos em marcenarias no município de Viçosa, MG [dissertação] Viçosa: Universidade Federal de Viçosa; 1999.
Silva, K. R. Análise de fatores ergonômicos em indústrias do pólo moveleiro de Ubá, MG [tese]. Viçosa: Universidade Federal de Viçosa; 2003.

University of Michigan. 3D Static Strength Prediction Program $^{\mathrm{TM}}$ : user's manual. Version 6.0.5. Ann Arbor: Center of Ergonomics; 2011. 108 p.

Waters TR, Putz-Anderson V, Garg A, Fine LJ. Revised NIOSH equation for the design and evaluation of manual lifting tasks. Ergonomics 1993; 36(7): 749-776. PMid:8339717. http://dx.doi.org/10.1080/00140139308967940. 